\title{
Inequalities in Health Status from EQ-5D Findings: A Cross-Sectional Study in Low-Income Communities of Bangladesh
}

\author{
Marufa Sultana ${ }^{{ }^{*}}$, Abdur Razzaque Sarker', Rashidul Alam Mahumud ${ }^{1}$, Sayem Ahmed ${ }^{1}$, Wahid Ahmed ${ }^{1}$, \\ Sanchita Chakrovorty ${ }^{1}$, Hafizur Rahman ${ }^{2}$, Ziaul Islam ${ }^{1}$, Jahangir A. M. Khan ${ }^{3,4}$
}

\begin{abstract}
Background: Measuring health status by using standardized and validated instrument has become a growing concern over the past few decades throughout the developed and developing countries. The aim of the study was to investigate the overall self-reported health status along with potential inequalities by using EuroQol 5 dimensions (EQ-5D) instrument among low-income people of Bangladesh.

Methods: A cross-sectional household survey was conducted in Chandpur district of Bangladesh. Bangla version of the EQ-5D questionnaire was employed along with socio-demographic information. EQ-5D questionnaire composed of 2-part measurements: EQ-5D descriptive system and the visual analogue scale (VAS). For measuring health status, UK-based preference weights were applied while higher score indicated better health status. For facilitating the consistency with EQ-5D score, VASs were converted to a scale with scores ranging from 0 to 1. Multiple logistic regression models were also employed to examine differences among EQ-5D dimensions.

Results: A total of 1433 respondents participated in the study. The mean EQ-5D and VAS score was 0.76 and 0.77 , respectively. The females were more likely to report any problem than the males $(P<0.001)$. Compared to the younger, elderly were more than 2-3 times likely to report any health problem in all EQ-5D dimensions (OR [odds ratio] $=3.17$ for mobility, $\mathrm{OR}=3.24$ for self-care). However, the respondents of the poorest income group were significantly suffered more from every EQ-5D dimension than the richest income quintile.

Conclusion: Socio-economic and demographic inequalities in health status was observed in the study. Study suggests to do further investigation with country representative sample to measure the inequalities of overall health status. It would be helpful for policy-maker to find a new way aiming to reduce such inequalities.

Keywords: Health Status, EQ-5D, Visual Analogue Scale (VAS), Inequality, Population

Copyright: @ 2016 by Kerman University of Medical Sciences

Citation: Sultana M, Sarker AR, Mahumud RA, et al. Inequalities in health status from EQ-5D findings: a cross-sectional study in low-income communities of Bangladesh. Int J Health Policy Manag. 2015;5(5):301-308. doi:10.15171/ijhpm.2016.06
\end{abstract}

Article History:

Received: 2 August 2015

Accepted: 14 January 2016 ePublished: 21 January 2016

\section{Key Messages}

Implications for policy makers

- The findings of the study can help policy-makers to find out the related factors of socio-economic and demographic inequalities in health status.

- It also can help policy-makers to find a new path way aiming to reduce such inequalities by making need-based supply side efficiency.

Implications for public

Study found that potential inequalities in health status exist among different socio-economic and demographic groups. Hence, factors affecting the health status should be assessed in order to improve the community health.

\section{Background}

Bangladesh has made notable gains across a range of social and health indicators, and has further experienced enhanced economic growth over the last 3 decades. According to article $15 \mathrm{a}$ in the constitution of Bangladesh, advocacy for human rights is considered as a fundamental priority as health and education. Moreover, Bangladesh has authorized most international agreements and declarations like Alma-Ata Declaration, Millennium Development Goals (MDGs), etc. ${ }^{1}$ Great achievements have also been made across many health indicators; all health indicators show steady gains and the health status of the population has improved. Infant mortality has decreased from 97.5 per 1000 live births in 1991 to 33 per 1000 live births in 2012 and mortality in children under 5 years of age has declined sharply from 151 per 1000 in 1991 to 41 per 1000 in $2012 .{ }^{2}$ This results in a remarkable increase in life expectancy at birth from 56.1 years in 1991 to 69 years in $2011 .{ }^{3}$ The rate of absolute poverty has also declined from $59 \%$ in $1991-1992$ to $31.5 \%$ in $2010 .{ }^{4}$ In fact, Bangladesh has already achieved MDG $3^{5}$ and is well on its way to achieving 
MDGs 1, 2, and 4 by $2015 .^{1}$

Despite such progress, however, there are still social health inequalities that continue to persist in Bangladesh. Poverty is higher in rural areas than in urban areas and the healthcare system caters to the rich, urban elite. In other words, the poor have less access to healthcare services than the rich. ${ }^{1,6,7}$ Therefore, in order to reduce health inequalities, the healthcare system should be operated in a way to allow for effective and affordable healthcare services to reach the rural and underprivileged communities of Bangladesh. Measuring health and its distribution among different groups within a population would provide valuable information about the health status of that population. Moreover, over the past few decades, there has been a growing concern for the need of a more systematic record on health status. ${ }^{8}$ Hence, measuring health status through a standardized and validated instrument is required for this country context that would help policy-makers in their efforts to provide need-based effective and affordable health services that have the potential to subsequently reduce inequalities in health.

EuroQol 5 dimensions (EQ-5D) is a standardized instrument for measuring health systematically and recording the health status for a group of individuals or a population. ${ }^{8}$ The EQ-5D instrument has widely been used in North America, Europe, and a few low- and middle-income countries in Asia and Africa. ${ }^{9-15}$ In Bangladesh, a few studies have used the EQ-5D instrument for measuring health status. This instrument was employed by Saleh et $\mathrm{al}^{16}$ to measure the health-related quality of life among patients with type 2 diabetes and used Shaheen and Lindholm ${ }^{17}$ to measure the quality of life among pregnant women with chronic energy deficiency in rural Bangladesh. Measurement of health status for the general population was not provided in those studies. As such, the aim of the present study was to investigate the overall health status and potential inequalities in the health status of people of varying demographic and socio-economic conditions in low-income communities in Bangladesh.

\section{Methods}

Study Area

This study was conducted in 14 Unions (lower administrative in rural) and a municipality in the Chandpur subdistrict of Bangladesh, where a group of workers established a cooperative, named Labor Association for Social Protection (LASP). Seven closely located unions along with municipal area itself were included in the study. There were 98109 households in the subdistrict, of which 63.50\% (62296 households) occupied rural areas and the rest (35813 households) occupied urban areas ${ }^{4}$ within a $308.78 \mathrm{~km}^{2}$ area. Implementation of a self-financed health scheme among the informal workers (including self-employment) was ongoing there. This survey was conducted within the catchment area of the LASP.

\section{Study Population}

The study population was selected based on two major criteria. Firstly, the household had to be lower than the lowest taxable income bracket, and secondly, it had to have at least one blue-collar informal worker who also met the inclusion criteria. Matched households in terms of income, household member, and occupation within the catchment area of the cooperative were surveyed.

\section{Survey Procedure}

A cross-sectional household survey was conducted from April to June of 2014 within the catchment area of the LASP. Households were selected for the survey according to the inclusion criteria for being a member of this cooperative. A total of 1554 households within the catchment area of the LASP were approached to participate the study. About $92 \%$ of the respondents (one from each household), ie, 1433 respondents, were willing to participate in the study within a 3-month time period. Face-to-face interviews were carried out by trained and experienced interviewers. A pretested, standardized questionnaire was used to collect information from the respondents. Bangla version of the EQ-5D questionnaires was employed along with socio-demographic information. ${ }^{16}$ Socio-economic and demographic characteristics such as gender, age, marital status, family size, occupation, education, and household income were obtained during the survey.

Before conducting the survey, objectives of the study were explained to the respondents and anonymity and confidentiality were ensured. The individuals aged 18 and above were selected as respondents for this study. We interviewed the selected households according to availability and willingness of the respondents to participate. Informed written consent was obtained before conducting any given interview.

\section{EQ-5D Instrument}

The EQ-5D questionnaire was developed by the EuroQol group, a voluntary, multinational collaboration of European investigators, during $1990 .{ }^{18}$ It is applicable to a wide range of health conditions; it provides a self-report visual analogue scale (VAS) and a single index value for health status that can be used in population health surveys. ${ }^{19}$ An extensive amount of research has been carried out worldwide on general population using this instrument and it has provided data on population health characteristics over the last 26 years, ${ }^{19}$ since it was originally developed. This EQ-5D questionnaire consists of 2-part measurements: the EQ-5D descriptive system and the VAS. It is available in more than 160 translated versions and more than 25 languages. The EQ-5D descriptive system comprises of five dimensions: mobility, self-care, usual activities, pain/discomfort, and anxiety/depression. The EQ$5 \mathrm{D}$ is available in three levels: no problems, some problems, and severe problems/unable to. The VAS provides a self-rating on a $20-\mathrm{cm}$ vertical scale with endpoints of 'best imaginable health state' set at ' 100 ' and 'worst imaginable health state' set at ' $0 .{ }^{\prime}$ For this study, the Bangla version for Bangladesh was used for measuring the health of the population. For EQ$5 \mathrm{D}$ self-completion, the respondents were asked to indicate his/her health state by ticking (or placing a cross) in the box against the most appropriate statement in each of the five dimensions. In the case of the valuation, the respondents were asked to value the same EQ-5D health states on the VAS, ranging from 0 to 100 , to indicate how well or bad his/ her own overall health status was in that day, where a higher score indicating a better self-reported, overall health status. ${ }^{8}$ 
The developers of the EQ-5D have generated value sets in several countries to calculate a preference-based index for the 243 health states defined by responses to the 5 questions of the EQ-5D, using a scale on which 0.0 represents being dead and 1.0 full health where with more severe health condition it would be negative value (upto -0.59) as well. ${ }^{16}$ The bestknown preference weights were derived from samples of the United Kingdom, which is the original population for estimating EQ-5D index scores. ${ }^{20}$ In this study, the UK-based preference weights are applied, as country-specific population preference-based weights are not available for Bangladesh. ${ }^{16}$ The responses in each dimension were classified into three levels of severity: 1 indicates "no problem," 2 indicates "some problem," and 3 indicates "extreme problem." For analysis, we converted the three levels of responses into two categories: (1) any problem (including "level 2" and "level 3"), and (2) no problem, since studies have shown that the EQ-5D instrument had ceiling effects in measuring the health status of general population. ${ }^{8,21}$ The health status in each dimension was presented as a percentage of the respondents reporting any problem in the corresponding dimension. The VAS score was firstly analyzed considering a range from 0-100, and later, for facilitating the consistency with EQ-5D score, the VASs were converted to a scale with scores ranging from 0 to 1 , after dividing it by 100 .

\section{Statistical Analysis}

The percentages of respondents reporting any problem in each EQ-5D dimension were calculated. Chi-square test was performed to find out if an association in each of the EQ$5 \mathrm{D}$ dimensions existed between groups. Independent two sample $t$ tests (or one-way analysis of variance [ANOVA] where appropriate) were used to find the association between different socio-economic and demographic characteristics on the EQ-5D index and the VAS score. Using logistic regression models, the likelihood of having any problem in each dimension was analyzed for all socio-economic and demographic characteristics after controlling for other influencing variables. Finally, unadjusted and adjusted multiple linear regression was performed to find the effect on the VAS score by explanatory variables. The Breusch-Pagan/ Cook-Weisberg test and the variance inflation factor (VIF) test were conducted to determine whether heteroscedasticity and multicollinearity were present or not. The Ramsey RESET test was performed to diagnose if there was any specification error of the model. For all the tests conducted in the study, a $P$ value of 0.05 or below was adopted as the statistically significant level. All statistical analyses were performed by using STATA version 13.0.

\section{Results}

Demographic and Socio-economic Characteristics of Respondents

Table 1 shows the demographic and socio-economic characteristics of respondents. Among respondents, $82.83 \%$ were male and $17.17 \%$ were female. The majority of the respondents (63.10\%) were 18-44 years old followed by $31.82 \%$ of the respondents being aged $45-64$ years old. $45.92 \%$ had primary level education and $33.15 \%$ had secondary level education. More than $90 \%$ of respondents were married. The
Table 1. Demographic and Socio-economic Characteristics of the Respondents

\begin{tabular}{|c|c|c|c|c|}
\hline \multirow{2}{*}{ Variables } & \multicolumn{2}{|l|}{ Total } & \multicolumn{2}{|c|}{$95 \% \mathrm{Cl}$} \\
\hline & $\%$ & No. & Low & Upper \\
\hline \multicolumn{5}{|l|}{ Gender } \\
\hline Male & 82.83 & 1,187 & 80.79 & 84.80 \\
\hline Female & 17.17 & 246 & 15.29 & 19.21 \\
\hline \multicolumn{5}{|l|}{ Age group } \\
\hline $18-44$ & 63.08 & 904 & 60.55 & 65.55 \\
\hline $45-64$ & 31.82 & 456 & 29.46 & 34.28 \\
\hline$>65$ & 5.09 & 73 & 4.07 & 6.36 \\
\hline \multicolumn{5}{|l|}{ Highest education level } \\
\hline No education & 13.12 & 188 & 11.47 & 14.97 \\
\hline Primary & 45.92 & 658 & 43.35 & 48.51 \\
\hline Secondary & 33.15 & 475 & 30.75 & 35.63 \\
\hline Higher secondary & 4.82 & 69 & 3.75 & 5.91 \\
\hline Above higher secondary & 3.00 & 43 & 2.23 & 3.92 \\
\hline \multicolumn{5}{|l|}{ Marital status } \\
\hline Married & 90.37 & 1295 & 88.82 & 91.89 \\
\hline Unmarried & 7.05 & 101 & 5.76 & 8.93 \\
\hline Widowed/divorced/separated & 2.58 & 37 & 1.83 & 3.38 \\
\hline \multicolumn{5}{|l|}{ Occupation } \\
\hline Worker & 33.71 & 483 & 31.30 & 36.19 \\
\hline Self-employed & 20.87 & 299 & 18.83 & 23.05 \\
\hline House wife & 13.54 & 194 & 11.84 & 15.39 \\
\hline Farmer & 9.49 & 136 & 8.07 & 11.12 \\
\hline Services & 14.72 & 211 & 12.93 & 16.64 \\
\hline Other & 7.68 & 110 & 6.34 & 9.17 \\
\hline \multicolumn{5}{|l|}{ Income quintile ${ }^{a}$} \\
\hline 1st ( $\leq$ US\$67) & 24.56 & 352 & 22.32 & 26.85 \\
\hline 2nd (US\$67.1-125.5) & 15.70 & 225 & 13.83 & 17.64 \\
\hline 3rd (US\$125.6-172.5) & 24.15 & 346 & 21.92 & 26.43 \\
\hline 4th (US\$172.6-232.5) & 16.61 & 238 & 14.74 & 18.53 \\
\hline 5th (US\$232.6+) & 18.98 & 272 & 16.91 & 21.09 \\
\hline
\end{tabular}

aUS\$1 = BDT 78 in 2014.

respondents were distributed into the five income quintiles; notably $24.56 \%$ were in the poorest, while $19 \%$ were in richest quintiles. Furthermore, among the respondents, workers accounted for $33.71 \%$ and the rest were self-employed, housewives, farmers, or other small service holders.

\section{Distribution of Self-reported (EQ-5D) Health States by} Gender

Figure shows the distribution of self-reported (EQ-5D) health states by gender. Three levels of the EQ-5D dimensions were reported by the participants. More than half of the respondents $(52.80 \%)$ indicated some problems in all five EQ-5D dimensions. As well, females reported that they suffered more than males (55.30\% vs. $52.80 \%$ ). About $16 \%$ of the female respondents had extreme problems across all dimensions.

Differences of the EQ-5D Dimensions and Visual Analogue Scale by Socio-Economic and Demographic Status

Table 2 shows the percentage of any health problem in each EQ-5D dimension and VAS score by socio-economic and demographic status of respondents. Results show that the elderly (65 and above year old) were more likely to report any problem in every EQ-5D dimension than those who were younger $(P<.001)$. Females were more likely to report any problem than males $(P<.001)$. The respondents who 


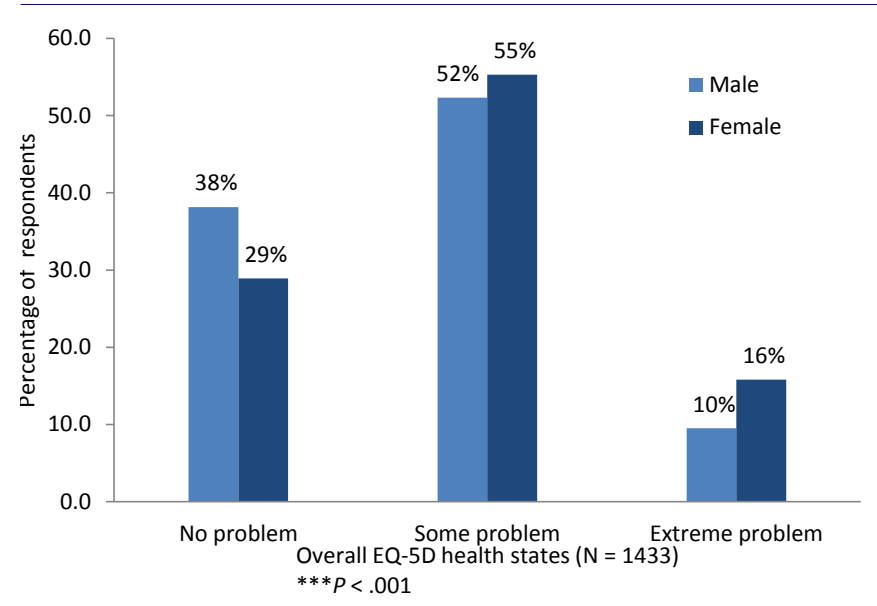

Figure. Distribution of Self-reported (EQ-5D) Health States by Gender.

were widowed/divorced/separated had lower EQ-5D and VAS scores compared to those who were married and unmarried $(P<.001)$. Compared with the educated, noneducated participants were more likely to suffer from usual activities $(P<.05)$. Compared to other occupational groups, the percentage reporting any problem in all dimensions were higher among housewives $(P<.001)$, which also showed average lower score of EQ-5D among all occupational groups. The respondents of the poorest income group were more likely to suffer from every EQ-5D dimension than the richest income quintile $(P<.001)$ and they also reported a lower VAS score.

Differences of the EQ-5D Dimensions by Using Multiple Logistic Regression Analysis

Table 3 showed the difference of the EQ-5D dimensions via logistic regression. The analysis suggested that respondents who were middle aged (45 to 64 years old) and elderly (65 or above years old) were more than 2 and 3 times likely to report any health problem in all EQ-5D dimensions compared to those who belonged to a younger age group (18 to 44 years). Unmarried respondents were more likely to report 'mobility' problems and respondents who were widowed/divorced/ separated experienced more problems in 'self-care' compared to married respondents. Housewives were three times more likely to report health problems in 'usual activities' compared to workers. The respondents of the poorest income quintile were significantly more likely to report any health problem in mobility, pain or discomfort, self-care, usual activities, and anxiety or depressions dimensions, as compared with the richest income quintile $(P<.001)$. All income groups except richest quintile stated health problems in anxiety or depression, pain or discomfort and self-care dimensions $(P<.05)$.

Differences of Visual Analog Scale Score by Socio-Economic and Demographic Status

Table 4 shows the results of the multiple regression analysis on VAS scores by demographic and socio-economic characteristics. The regression model explains $12.90 \%$ of the total variation $\left(\mathrm{R}^{2}=0.129\right)$. The Breusch-Pagan/CookWeisberg diagnostic test showed that heteroscedasticity was not present in the model. The VIF test with its mean (max) value of 3.73 (4.21) indicates that there is no evidence of a multicollinearity problem in the regression model. ${ }^{22}$ The Ramsey RESET test showed that there is sufficient evidence against the hypothesis of omitted variable bias in the model. The younger respondents (18-44 years old) tended to report a higher VAS score than their middle aged and elderly counterparts $(-0.06,95 \% \mathrm{CI}:-0.08,-0.04)$ and $(-0.05,95 \%$ CI: $-0.10,-0.01)$, respectively. This result suggested that one year-band increase of age of middle aged and elderly in the VAS score decreased by 0.06 units and 0.05 units, respectively $(P<.05)$. Compared with those in the higher income group, the respondents in the lower income groups tended to report smaller VAS scores $(P<.05)$.

\section{Discussion}

This study was conducted among households with at least one blue-collar informal worker to measure the health status of this community. These informal sector workers have different types of occupations ie, farmer, rickshaw puller, van driver, as well as self-employed (eg, small business), where there may be income variation. This study provided the health status of the low-income population of selected communities in Bangladesh measured by the EQ-5D instrument and it also investigated the inequalities in health status among people in low-income communities.

The current study found that the poorest income group were more likely to suffer from every EQ-5D dimension than the richest income quintile, which is consistent with findings from other studies. ${ }^{8,10}$ We also found that the health status was lower in the elderly and female populations, which is similar to EQ-5D population health status studies in other countries. ${ }^{10,13,23-25}$ This study found housewives to have a lower quality of life than individuals with other occupations. This may be due to their low level of education, in most cases. During the survey, we found that in most cases households, and frequently participated the study than the female. Also, the patriarchy social system might be the cause of under representativeness of the female respondents that did not represent the true distribution of population. In addition, healthcare utilization was clearly age dependent, which suggested that the ageing population utilized more healthcare services than the younger. ${ }^{26}$

Different studies indicated that individuals with higher educational levels were likely to report better health status with a higher VAS score. ${ }^{8,10}$ Studies reported that education has a direct influence on health status as educated people usually have better knowledge about health, the healthcare system, and have also better access and utilization of healthcare services..$^{27-29}$ In contrast, our study showed that education did not have any significant impact on EQ-5D and VAS score. Compared to the married respondents, the singles were less likely to suffer from EQ-5D dimensions. This may be due to younger age, as we found a negative relationship between health status and age in this study, or it may be due to influenced by other factors like income, education, etc. Dissimilar from our findings, a study in China reported that singles suffered more from mobility and usual activities. ${ }^{8}$ Other studies also commonly found that the married tend to live longer and healthier lives than the singles. ${ }^{30,31}$ This incongruous finding might need further investigation. 
Table 2. Percentage of Respondents Reporting Some or Extreme Problems in each EQ-5D Dimensions by Demographic and Socio-Economic Characteristics $(\mathrm{N}=1433)$

\begin{tabular}{|c|c|c|c|c|c|c|c|c|c|c|c|c|c|c|}
\hline \multirow[b]{2}{*}{ Indicators } & \multicolumn{2}{|c|}{ Mobility } & \multicolumn{2}{|c|}{ Self-care } & \multicolumn{2}{|c|}{ Usual Activities } & \multicolumn{2}{|c|}{ Pain or Discomfort } & \multicolumn{2}{|c|}{ Anxiety or Depressions } & \multicolumn{2}{|c|}{ EQ-5D Score } & \multicolumn{2}{|c|}{ VAS } \\
\hline & $\begin{array}{l}\% \text { Of any } \\
\text { Problem }\end{array}$ & $x^{2}$-Value & $\begin{array}{l}\text { \% Of any } \\
\text { Problem }\end{array}$ & $\chi^{2}$-Value & $\begin{array}{l}\text { \% Of any } \\
\text { Problem }\end{array}$ & $x^{2}$-Value & $\begin{array}{l}\text { \% Of any } \\
\text { Problem }\end{array}$ & $\chi^{2}$-Value & $\begin{array}{l}\text { \% Of any } \\
\text { Problem }\end{array}$ & $\chi^{2}$-Value & Mean (SD) & $\begin{array}{l}\text { Test- } \\
\text { Statistic }\end{array}$ & Mean (SD) & Test-Statistic \\
\hline \multicolumn{15}{|l|}{ Gender } \\
\hline Male & $259(21.82)$ & \multirow{2}{*}{$20.42^{\mathrm{a}}$} & $135(11.37)$ & \multirow{2}{*}{$26.04^{\mathrm{a}}$} & $309(26.03)$ & \multirow{2}{*}{$14.95^{\mathrm{a}}$} & $505(42.54)$ & \multirow{2}{*}{$13.38^{\mathrm{a}}$} & $618(52.06)$ & \multirow{2}{*}{$3.43^{b}$} & $0.77(0.28)$ & \multirow{2}{*}{$5.23^{c}$} & $0.77(0.18)$ & \multirow{2}{*}{$3.59^{c}$} \\
\hline Female & $87(35.37)$ & & $58(23.58)$ & & $94(38.21)$ & & $136(55.28)$ & & $144(58.54)$ & & $0.68(0.35)$ & & $0.76(0.20)$ & \\
\hline \multicolumn{15}{|l|}{ Age group } \\
\hline $18-44$ & $171(18.92)$ & \multirow{3}{*}{$43.36^{\mathrm{a}}$} & $99(10.95)$ & \multirow{3}{*}{$18.27^{\mathrm{a}}$} & $204(22.57)$ & \multirow{3}{*}{$40.76^{\mathrm{a}}$} & $353(39.05)$ & \multirow{3}{*}{$33.76^{\mathrm{a}}$} & $434(48.01)$ & \multirow{3}{*}{$26.73^{\mathrm{a}}$} & $0.79(0.27)$ & \multirow{3}{*}{$3.26^{\mathrm{a}, \mathrm{d}}$} & $0.79(0.18)$ & \multirow{3}{*}{$8.93^{\mathrm{a}, \mathrm{d}}$} \\
\hline $45-64$ & $142(31.15)$ & & 75 (16.45) & & $165(36.18)$ & & $243(53.29)$ & & $280(61.40)$ & & $0.70(0.31)$ & & $0.74(0.19)$ & \\
\hline$>65$ & $33(45.21)$ & & $19(26.03)$ & & $34(46.58)$ & & $45(61.64)$ & & $48(65.78)$ & & $0.63(0.38)$ & & $0.74(0.21)$ & \\
\hline \multicolumn{15}{|l|}{ Highest education level } \\
\hline No education & $51(27.13)$ & & $32(17.02)$ & & $59(31.38)$ & & $78(41.49)$ & & $100(53.19)$ & & $0.74(0.34)$ & & $0.78(0.19)$ & \\
\hline Primary & $167(25.38)$ & & 96 (14.59) & & $202(30.70)$ & & 309 (46.96) & & $358(54.41)$ & & $0.74(0.30)$ & & $0.76(0.19)$ & \\
\hline Secondary & $108(22.74)$ & 4.41 & $55(11.58)$ & 6.19 & $120(25.26)$ & $9.45^{b}$ & $212(44.63)$ & 5.18 & $243(51.16)$ & 2.14 & $0.77(0.26)$ & $4.29^{\mathrm{a}, \mathrm{d}}$ & $0.79(0.18)$ & $5.29^{\mathrm{b}, \mathrm{d}}$ \\
\hline Higher secondary & $12(17.39)$ & & $6(8.70)$ & & $15(21.74)$ & & $28(40.58)$ & & $40(57.97)$ & & $0.77(0.28)$ & & $0.78(0.20)$ & \\
\hline Above higher secondary & $8(18.60)$ & & $4(9.30)$ & & $7(16.28)$ & & $14(32.56)$ & & $21(48.84)$ & & $0.81(0.30)$ & & $0.80(0.20)$ & \\
\hline Marital status & & & & & & & & & & & & & & \\
\hline Married & $321(24.79)$ & & $181(13.98)$ & & $371(28.65)$ & & $591(45.64)$ & & $698(53.90)$ & & $0.75(0.29)$ & & $0.77(0.19)$ & \\
\hline Unmarried & $10(9.90)$ & $16.91^{\mathrm{a}}$ & $5(4.95)$ & $7.52^{\mathrm{b}}$ & $14(13.86)$ & $18.05^{\mathrm{a}}$ & $29(28.71)$ & $13.08^{\mathrm{a}}$ & $42(41.58)$ & $6.31^{\mathrm{b}}$ & $0.83(0.29)$ & $8.52^{\mathrm{d}}$ & $0.82(0.17)$ & $8.19^{\mathrm{a}, \mathrm{d}}$ \\
\hline Widowed/divorced/Separated & $15(40.54)$ & & $7(18.92)$ & & $18(48.65)$ & & $21(56.76)$ & & $22(59.46)$ & & $0.62(0.44)$ & & $0.68(0.23)$ & \\
\hline Occupation & & & & & & & & & & & & & & \\
\hline Worker & $91(18.84)$ & & $54(11.18)$ & & $113(23.40)$ & & $196(40.58)$ & & $243(50.31)$ & & $0.77(0.28)$ & & $0.77(0.19)$ & \\
\hline Self-employed & 67 (22.41) & & 35 (11.71) & & 78 (26.09) & & $129(43.14)$ & & $148(49.50)$ & & $0.78(0.28)$ & & $0.78(0.19)$ & \\
\hline House wife & $69(35.57)$ & 20 ога & $47(24.23)$ & $2077 \mathrm{a}$ & $79(40.72)$ & 22790 & $108(55.67)$ & $2352^{\mathrm{a}}$ & $116(59.79)$ & $122^{\mathrm{b}}$ & $0.68(0.33)$ & 6 & $0.77(0.19)$ & $11 \mathrm{bd}^{\mathrm{d}}$ \\
\hline Farmer & $44(32.35)$ & $34.85^{\circ}$ & 19 (13.97) & $28.7 / 7^{5}$ & $50(36.76)$ & $33.28^{\circ}$ & 75 (55.15) & $23.53^{\circ}$ & 81 (59.56) & $12.22^{\circ}$ & $0.73(0.26)$ & $6.22^{9,4}$ & $0.75(0.18)$ & $6.11^{1,0}$ \\
\hline Services & $39(18.48)$ & & $18(8.53)$ & & $45(21.33)$ & & $80(37.91)$ & & $122(57.82)$ & & $0.80(0.25)$ & & $0.78(0.17)$ & \\
\hline Other & $36(32.73)$ & & $20(18.18)$ & & $38(34.55)$ & & $53(48.18)$ & & $52(47.27)$ & & $0.69(0.38)$ & & $0.76(0.20)$ & \\
\hline Income quintile & & & & & & & & & & & & & & \\
\hline 1st & $122(34.66)$ & & 79 (22.44) & & 134 (38.07) & & 194 (55.11) & & $236(67.05)$ & & $0.66(0.36)$ & & $0.73(0.20)$ & \\
\hline 2nd & $45(20.00)$ & & $28(12.44)$ & & $53(23.56)$ & & $103(45.78)$ & & 119 (52.89) & & $0.74(0.32)$ & & $0.78(0.17)$ & \\
\hline $3 r d$ & $70(20.23)$ & $28.45^{a}$ & 39 (11.27) & $35.61^{\mathrm{a}}$ & $87(25.14)$ & $23.65^{\mathrm{a}}$ & $153(44.22)$ & $26.68^{\mathrm{a}}$ & $174(50.29)$ & $49.28^{\mathrm{a}}$ & $0.79(0.25)$ & $8.53^{a, d}$ & $0.77(0.19)$ & $4.53^{3, d}$ \\
\hline 4th & $52(21.85)$ & & 27 (11.34) & & $64(26.89)$ & & $92(38.66)$ & & $126(52.94)$ & & $0.80(0.24)$ & & $0.79(0.18)$ & \\
\hline 5 th & $57(20.96)$ & & $20(7.35)$ & & $65(23.90)$ & & $99(36.40)$ & & $107(39.34)$ & & $0.83(0.24)$ & & $0.81(0.18)$ & \\
\hline Overall & 346 (24.15) & & $193(13.47)$ & & $403(28.12)$ & & $641(44.73)$ & & 762 (53.18) & & $0.76(0.29)$ & & $0.77(0.19)$ & \\
\hline
\end{tabular}

Abbreviations: VAS, visual analogue scale; EQ-5D, EuroQol 5 dimensions.

denotes $1 \%$ significance level.

'Independent two samples $t$ test was performed to derive significance level.

${ }^{d}$ One-way analysis of variance (ANOVA) was performed to derive significance level. 
Table 3. Logistic Regression Analysis on Reported any Problems in EQ-5D Dimensions

\begin{tabular}{|c|c|c|c|c|c|c|c|c|c|c|}
\hline \multirow{2}{*}{ Indicators } & \multicolumn{2}{|c|}{ Mobility } & \multicolumn{2}{|c|}{ Self-care } & \multicolumn{2}{|c|}{ Usual Activities } & \multicolumn{2}{|c|}{ Pain or Discomfort } & \multicolumn{2}{|c|}{ Anxiety or Depressions } \\
\hline & OR & $95 \% \mathrm{Cl}(\mathrm{OR})$ & OR & $95 \% \mathrm{Cl}(\mathrm{OR})$ & OR & $95 \% \mathrm{Cl}(\mathrm{OR})$ & OR & $95 \% \mathrm{Cl}(\mathrm{OR})$ & OR & $95 \% \mathrm{Cl}$ (OR) \\
\hline \multicolumn{11}{|l|}{ Gender } \\
\hline Male (Ref) & 1.00 & - & 1.00 & - & 1.00 & - & 1.00 & - & 1.00 & - \\
\hline Female & 1.52 & $(0.77,3.01)$ & 1.85 & $(0.83,4.14)$ & 0.77 & $(0.38,1.57)$ & 1.57 & $(0.84,2.93)$ & 1.05 & $(0.564,1.964)$ \\
\hline \multicolumn{11}{|l|}{ Age group } \\
\hline 18-44 (Ref) & 1.00 & - & 1.00 & - & 1.00 & - & 1.00 & - & 1.00 & - \\
\hline $45-64$ & $2.04^{\mathrm{a}}$ & $(1.52,2.73)$ & $2.02^{\mathrm{a}}$ & $(1.40,2.93)$ & $2.01^{a}$ & $(1.52,2.66)$ & $2.02^{\mathrm{a}}$ & $(1.56,2.61)$ & $1.99^{\mathrm{a}}$ & $(1.53,2.58)$ \\
\hline$>65$ & $3.17^{\mathrm{a}}$ & $(1.85,5.43)$ & $3.25^{\mathrm{a}}$ & $(1.71,6.18)$ & $2.75^{\mathrm{a}}$ & $(1.62,4.68)$ & $2.74^{\mathrm{a}}$ & $(1.61,4.66)$ & $2.52^{\mathrm{a}}$ & $(1.46,4.36)$ \\
\hline \multicolumn{11}{|l|}{ Highest education level } \\
\hline No education & 0.98 & $(0.40,2.39)$ & 1.01 & $(0.31,3.26)$ & 1.53 & $(0.61,3.85)$ & 0.80 & $(0.38,1.71)$ & 0.77 & $(0.37,1.58)$ \\
\hline Primary & 1.06 & $(0.45,2.46)$ & 0.91 & $(0.30,2.77)$ & 1.74 & $(0.73,4.15)$ & 1.21 & $(0.60,2.45)$ & 0.94 & $(0.48,1.83)$ \\
\hline Secondary & 1.00 & $(0.44,2.29)$ & 0.78 & $(0.26,2.36)$ & 1.40 & $(0.59,3.33)$ & 1.25 & $(0.63,2.50)$ & 0.90 & $(0.47,1.74)$ \\
\hline Higher secondary & 0.86 & $(0.31,2.38)$ & 0.69 & $(0.18,2.71)$ & 1.41 & $(0.51,3.92)$ & 1.30 & $(0.57,2.96)$ & 1.27 & $(0.57,2.82)$ \\
\hline Above Higher secondary (Ref) & 1.00 & - & 1.00 & - & 1.00 & - & 1.00 & - & 1.00 & - \\
\hline \multicolumn{11}{|l|}{ Marital status } \\
\hline Married (Ref) & 1.00 & - & 1.00 & - & 1.00 & - & 1.00 & - & 1.00 & - \\
\hline Unmarried & $0.56^{c}$ & $(0.28,1.13)$ & 0.60 & $(0.23,1.57)$ & 0.68 & $(0.37,1.24)$ & 0.75 & $(0.47,1.20)$ & 0.91 & $(0.59,1.42)$ \\
\hline Widowed/divorced/separated & 0.89 & $(0.39,1.99)$ & 0.44 & $(0.16,1.19)$ & 1.53 & $(0.68,3.43)$ & 0.89 & $(0.41,1.93)$ & 0.83 & $(0.380,1.83)$ \\
\hline Worker (Ref) & 1.00 & - & 1.00 & - & 1.00 & - & 1.00 & - & 1.00 & - \\
\hline Self-employed & 1.24 & $(0.85,1.82)$ & 1.14 & $(0.71,1.86)$ & 1.18 & $(0.83,1.69)$ & 1.11 & $(0.81,1.52)$ & 1.00 & $(0.73,1.37)$ \\
\hline House wife & 1.67 & $(0.79,3.54)$ & 1.67 & $(0.69,4.04)$ & $3.13^{\mathrm{a}}$ & $(1.44,6.77)$ & 1.21 & $(0.61,2.40)$ & 1.41 & $(0.71,2.81)$ \\
\hline Farmer & 1.38 & $(0.88,2.17)$ & 0.87 & $(0.48,1.58)$ & 1.34 & $(0.87,2.07)$ & 1.28 & $(0.85,1.93)$ & 1.03 & $(0.68,1.55)$ \\
\hline Services & 1.01 & $(0.63,1.61)$ & 0.80 & $(0.43,1.49)$ & 0.99 & $(0.64,1.53)$ & 0.87 & $(0.60,1.27)$ & 1.34 & $(0.92,1.94)$ \\
\hline Other & $1.73^{b}$ & $(1.03,2.91)$ & 1.67 & $(0.87,3.18)$ & $1.67^{\mathrm{b}}$ & $(1.01,2.75)$ & 1.21 & $(0.76,1.91)$ & 0.83 & $(0.52,1.31)$ \\
\hline \multicolumn{11}{|l|}{ Income quintile } \\
\hline 1st & $2.01^{\mathrm{a}}$ & $(1.32,3.04)$ & $3.47^{\mathrm{a}}$ & $(1.95,6.17)$ & $1.79^{\mathrm{a}}$ & $(1.20,2.67)$ & $2.33^{\mathrm{a}}$ & $(1.62,3.37)$ & $3.59^{\mathrm{a}}$ & $(2.47,5.20)$ \\
\hline $2 n d$ & 1.09 & $(0.69,1.75)$ & $2.04^{b}$ & $(1.08,3.87)$ & 1.05 & $(0.67,1.63)$ & $1.74^{\mathrm{b}}$ & $(1.18,2.56)$ & $2.02^{\mathrm{a}}$ & $(1.38,2.96)$ \\
\hline $3 \mathrm{rd}$ & 1.11 & $(0.72,1.68)$ & $1.80^{\mathrm{b}}$ & $(0.99,3.27)$ & 1.15 & $(0.77,1.71)$ & $1.63^{\mathrm{b}}$ & $(1.15,2.32)$ & $1.80^{\mathrm{a}}$ & $(1.27,2.54)$ \\
\hline 4th & 1.11 & $(0.71,1.73)$ & 1.71 & $(0.91,3.20)$ & 1.18 & $(0.77,1.79)$ & 1.17 & $(0.81,1.71)$ & $1.81^{\mathrm{a}}$ & $(1.25,2.61)$ \\
\hline 5th (Ref) & 1.00 & - & 1.00 & - & 1.00 & - & 1.00 & - & 1.00 & - \\
\hline
\end{tabular}

Abbreviations: EQ-5D, EuroQol 5 dimensions, OR, odds ratio.

a denotes $1 \%$ significance level.
bdenotes $5 \%$ significance level. 
Table 4. Multiple Regression Analysis on VAS Score by Demographic and Socio-Economic Characteristics

\begin{tabular}{|c|c|c|c|c|}
\hline \multirow{2}{*}{ Variables } & \multicolumn{2}{|c|}{ Unadjusted } & \multicolumn{2}{|c|}{ Adjusted } \\
\hline & Co-efficient & $95 \% \mathrm{Cl}$ & Co-efficient & $95 \% \mathrm{Cl}$ \\
\hline \multicolumn{5}{|l|}{ Gender } \\
\hline Male (Ref) & 0.00 & - & 0.00 & - \\
\hline Female & -0.01 & $(-0.04,0.02)$ & -0.01 & $(-0.07,0.04)$ \\
\hline \multicolumn{5}{|l|}{ Age group } \\
\hline 18-44 (Ref) & 0.00 & - & 0.00 & - \\
\hline$>65$ & $-0.06^{b}$ & $(-0.10,-0.01)$ & $-0.05^{b}$ & $(-0.01,-0.01)$ \\
\hline \multicolumn{5}{|l|}{ Highest education level } \\
\hline No education & -0.02 & $(-0.08,0.04)$ & 0.03 & $(-0.03,0.10)$ \\
\hline Primary & -0.05 & $(-0.10,0.01)$ & -0.01 & $(-0.07,0.05)$ \\
\hline Secondary & -0.01 & $(-0.07,0.05)$ & 0.01 & $(-0.05,0.07)$ \\
\hline Higher secondary & -0.02 & $(-0.09,0.05)$ & -0.01 & $(-0.08,0.06)$ \\
\hline Higher (Ref) & 1.00 & - & 1.00 & - \\
\hline Married (Ref) & 0.00 & - & 0.00 & - \\
\hline Unmarried & $0.05^{\mathrm{a}}$ & $(0.02,0.09)$ & 0.02 & $(-0.02,0.06)$ \\
\hline Widowed/divorced/separated (Ref) & $-0.09^{b}$ & $(-0.15,-0.03)$ & -0.06 & $(-0.13,0.01)$ \\
\hline \multicolumn{5}{|l|}{ Occupation } \\
\hline Worker (Ref) & 0.00 & - & 0.00 & - \\
\hline Self-employed & 0.02 & $(-0.01,0.04)$ & 0.01 & $(-0.02,0.04)$ \\
\hline House wife & 0.00 & $(-0.03,0.04)$ & 0.02 & $(-0.04,0.08)$ \\
\hline Farmer & -0.02 & $(-0.05,0.02)$ & 0.01 & $(-0.03,0.04)$ \\
\hline Services & 0.02 & $(-0.02,0.05)$ & 0.01 & $(-0.02,0.05)$ \\
\hline Other & -0.01 & $(-0.05,0.02)$ & -0.01 & $(-0.05,0.03)$ \\
\hline \multicolumn{5}{|l|}{ Income quintile } \\
\hline 1st & $-0.09^{a}$ & $(-0.12,-0.06)$ & $-0.09^{a}$ & $(-0.12,-0.05)$ \\
\hline 2nd & $-0.03^{b}$ & $(-0.06,-0.00)$ & $-0.04^{b}$ & $(-0.07,-0.00)$ \\
\hline 5 th (ref) & 0.00 & - & 0.00 & - \\
\hline
\end{tabular}

Abbreviations: VAS, visual analogue scale.

$\mathrm{N}=1433$; R-squared = 0.06; F-value $(23,1409)$ (prob>F): $3.98(0.00)$; Mean VIF = 3.73; BP/ Cook-Weisberg test $\left(P>\chi^{2}\right): 6.84(0.01)$; Ramsey RESET, F $(P>\mathrm{F})$ : $2.97(0.03)$

The EQ-5D instrument for measuring the health status in low-income communities in Bangladesh showed a positive association between socio-economic variables like education and income level. The positive association between socioeconomic status and health also has been observed in other studies in Europe and Asia. ${ }^{8,32}$ Our study had similar findings where socio-economic inequalities were observed. Evidence also showed that GDP per capita and healthcare expenditure is correlated most with the EQ VAS score. ${ }^{19}$ However, Shafie et $\mathrm{al}^{12}$ showed that the health status was positively associated with education, but had no significant association with income.

The study has some limitations. The study was conducted in selected communities, which limits the generalizability of the findings, and thus, might not represent the health status of the whole Bangladeshi population. Furthermore, the high percentage of male respondents might cause the selection bias. All information was self-reported and thus the estimation might be subject to the respondent's status at the time of the interview, which might not capture the actual reflection of health status in all aspects.

\section{Conclusion}

This study measured the overall health status of the population of selected communities in Bangladesh. Socio-economic and demographic inequalities in health status were observed in the study. Further studies need to be carried out with country representative sample to measure the inequality of overall health status of the population. It would be helpful for policymakers to restructure the health system for reducing such inequalities.

\section{Acknowledgements}

icddr,b acknowledges with gratitude the Grand Challenges Canada (GCC) for funding the project. icddr,b is thankful to the Governments of Australia, Bangladesh, Canada, Sweden, and the United Kingdom for providing core/unrestricted support. Authors would like to thank Gourab Adhikary for his kind review and also thank to Khandaker Mohammad Zahid as well as field research assistants for their continuous support during this research.

\section{Ethical issues}

The research protocol was approved by the Research Review Committee (RRC) and the Ethical Review Committee (ERC) of the International Centre for Diarrhoeal Disease Research, Dhaka, Bangladesh (icddr,b).

\section{Competing interests}

The authors declare that they have no competing interests.

\section{Authors' contributions}

MS and ARS designed and planned the study. The study was coordinated by 
MS, ARS, RAM, SA, and JAMK. Data analysis was conducted by MS, ARS, RAM, and SA. Interpretation of the data was conducted by MS, ARS, RAM, SA, WA, SC, HR, ZI, and JAMK. The manuscript was drafted by MS, ARS, RAM, MS, SA, HR, ZI, and JAMK. All authors critically reviewed and approved the final manuscript.

\section{Authors' affiliations}

${ }^{1}$ Health Economics and Financing Research Group, Center for Equity and Health Systems, icddr,b, Dhaka, Bangladesh. ${ }^{2}$ Health Economics Unit, Ministry of Health and Family Welfare, Dhaka, Bangladesh. ${ }^{3}$ Liverpool School of Tropical Medicine, Liverpool, UK. ${ }^{4}$ Health Economics Unit, Department of Learning, Informatics, Management and Ethics (LIME), Karolinska Institutet, Stockholm, Sweden.

\section{References}

1. Khan $M M$, Krämer $A$, Khandoker $A$, Prüfer-Krämer L, Islam A. Trends in sociodemographic and health-related indicators in Bangladesh, 1993-2007: will inequities persist? Bull World Health Organ. 2011;89(8):583-593. doi:10.2471/blt.11.087429

2. Ministry of Health and Family Welfare (MoHFW). Health Bulletin 2013. Dhaka, Bangladesh: Management Information System, Directorate General of Health Services, 2013.

3. Ministry of Finance (MoF). Bangladesh Economic Review. Dhaka, Bangladesh: Government of the People's Republic of Bangladesh; 2014.

4. Bangladesh Bureau of Statistics (BBS). Bangladesh Household Income \& Expenditure Survey: Preliminary Results. Dhaka, Bangladesh: Statistics Division, Ministry of Planning; 2010

5. Ministry of Health and Family Welfare (MoHFW). Health Bulletin 2014. Dhaka, Bangladesh: Management Information System, Directorate General of Health Services; 2014.

6. Rahman RM. Human rights, health and the state in Bangladesh. BMC Int Health Hum Rights. 2006;6:4.

7. Chowdhury ME, Ronsmans C, Killewo J, et al. Equity in use of home-based or facility-based skilled obstetric care in rural Bangladesh: an observational study. Lancet. 2001;367:327-332. doi:10.1016/s0140-6736(06)68070-7

8. Li H, Wei X, Ma A, Chung RY. Inequalities in health status among rural residents: EQ-5D findings from household survey in China. Int J Equity Health. 2014;13(41):1-8. doi:10.1186/1475-9276-1341

9. Hoi LV, Chuc NT, Lindholm L. Health-related quality of life, and its determinants, among older people in rural Vietnam. BMC Public Health. 2010;10:459. doi:10.1186/1471-2458-10-549

10. Sun S, Chen J, Johannesson M, et al. Population health status in China: EQ-5D results, by age, sex and socio-economic status, from the National Health Services Survey 2008. Qual Life Res. 2011;20(3):309-320. doi:10.1007/s11136-010-9762-x

11. König $\mathrm{HH}$, Bernert $\mathrm{S}$, Angermeyer MC, et al. Comparison of population health status in six european countries: results of a representative survey using the EQ-5D questionnaire. Med Care. 2009;47(2):255-261. doi:10.1097/mlr.0b013e318184759e

12. Shafie AA, Hassali MA, Liau SY. A cross-sectional validation study of EQ-5D among the Malaysian adult population. Qual Life Res. 2011;20(4):593-600. doi:10.1007/s11136-010-9774-6

13. Luo N, Johnson JA, Shaw JW, Feeny D, Coons SJ. Selfreported health status of the general adult U.S. population as assessed by the EQ-5D and Health Utilities Index. Med Care. 2005;43(11):1078-1086. doi:10.1097/01.mlr.0000182493.57090. c1

14. Odil VU, Ugboka LU, Oparah AC. Quality Of Life Of People With Diabetes In Benin City As Measured With WHOQOL- BRE. Internet J Law Healthc Ethics. 2015;6(2):1-10.

15. Bajunirwe $\mathrm{F}$, Tisch DJ, King $\mathrm{CH}$, Arts EJ, Debanne SM,
Sethi AK. Quality of life and social support among patients receiving antiretroviral therapy in Western Uganda. AIDS Care. 2009;21(3):271-279. doi:10.1080/09540120802241863

16. Saleh F, Mumu SJ, Ara F, Hafez MA, Ali L. Non-adherence to self-care practices \& medication and health related quality of life among patients with type 2 diabetes: a cross-sectional study. BMC Public Health. 2014;14:431.

17. Shaheen R, Lindholm L. Quality of life among pregnant women with chronic energy deficiency in rural Bangladesh. Health Policy. 2006;78(2-3):128-134. doi:10.1016/j.healthpol.2005.11.008

18. Rabin R, De Charro F. EQ-SD: a measure of health status from. Ann Med. 2001;33:337-343. doi:10.3109/07853890109002087

19. Szende A, Janssen B, Cabases J. Self-Reported Population Health: An International Perspective Based on EQ-5D. Springer open; 2014.

20. Sakthong $P$, Charoenvisuthiwongs $R$, Shabunthom R. A comparison of EQ-5D index scores using the UK, US, and Japan preference weights in a Thai sample with type 2 diabetes. Health Qual Life Outcomes 2008;6:71. doi:10.1186/1477-7525-6-71

21. Bharmal M, Thomas J. Comparing the EQ-5D and the SF6D descriptive systems to assess their ceiling effects in the US general population. Value Health. 2006;9(4):262-271. doi:10.1111/j.1524-4733.2006.00108.x

22. Hossain M, Saw A, Alam R, Ohtsuki F, Kamarul T. Multiple regression analysis of anthropometric measurements influencing the cephalic index of male Japanese university students. Singapore Med J. 2013;54(9):516-520. doi:10.11622/ smedj.2013175

23. Golicki D, Niewada M, Jakubczyk M, Wrona W, Hermanowski T. Self-assessed health status in Poland: EQ-5D findings from the Polish valuation study. Value Health 2008;11(6): A566-A567. doi:10.1016/s1098-3015(10)66863-5

24. Ebenbichler GR, Resch KL, Nicolakis $P$, et al. Ultrasound treatment for treating the carpal tunnel syndrome: randomised "sham" controlled trial. BMJ. 1998;316:731. doi:10.1136/ bmj.316.7133.731

25. Burström K, Johannesson M, Diderichsen F. Swedish population health-related quality of life results using the EQ-5D. Qual Life Res. 2001;10(7):621-635. doi:10.1007/s11136-007-9243-z

26. Sarker AR, Mahumud RA, Sultana M, Ahmed S, Ahmed W, Khan JA. The impact of age and sex on healthcare expenditure of households in Bangladesh. Springer plus. 2014;3(1):435. doi:10.1186/2193-1801-3-435

27. Alberts JF, Sanderman R, Eimers JM, van den Heuvel WJ. Socioeconomic inequity in health care: a study of services utilization in Curaçao. Soc Sci Med. 1997;45(2):213-220. doi:10.1016/s0277-9536(96)00338-3

28. Mclsaac W, Goel V, Naylor D. Socio-economic status and visits to physicians by adults in Ontario, Canada. $J$ Health Serv Res Policy. 1997;2(2):94-102.

29. Ross CE, Wu C. The links between education and health. Am Sociol Rev. 1995;60(5):719.

30. Cheung YB. Marital status and mortality in British women: a longitudinal study. Int $J$ Epidemiol. 2000;29(1):93-99. doi:10.1093/ije/29.1.93

31. Johnson NJ, Backlund E, Sorlie PD, Loveless CA. Marital status and mortality: The National Longitudinal Mortality Study. Ann Epidemiol. 2000;10(4):224-238. doi:10.1016/s10472797(99)00052-6

32. Mackenbach JP, Kunst AE. Measuring the magnitude of socioeconomic inequalities in health: An overview of available measures illustrated with two examples from Europe. Soc Sci Med. 1997;44(6):757-771. doi:10.1016/s0277-9536(96)00073-1 